\title{
Epidemiology, Prevention and Control Strategies of Coronavirus COVID 19 in Iran: A Systematic Review
}

\author{
Monireh Rezaee Moradali ${ }^{1}$, Masoumeh Simbar ${ }^{2 *}$, Sahar Roozbahani ${ }^{1}$, Fatemeh Yahyavi Koochaksaraei ${ }^{1}$, Pooya Hosseinzadeh $^{3}$, \\ MoradAli Zareipour ${ }^{4}$, Fatemeh Bayat ${ }^{1}$, Maryam Amighi ${ }^{1}$, Hadis Shahrahmani ${ }^{1}$ \\ ${ }^{1}$ Student Research Committee, School of Nursing and Midwifery, Shahid Beheshti University of Medical Sciences, Tehran, \\ Iran; ${ }^{2}$ Midwifery and Reproductive Health Research Center, Department of Midwifery and Reproductive Health, School of \\ Nursing and Midwifery, Shahid Beheshti University of Medical Sciences, Tehran, Iran; ${ }^{3}$ Department of Nursing and Midwifery, \\ Urmia Branch, Islamic Azad University, Urmia, Iran; ${ }^{4}$ Health System Research Unit, Health Center of Urmia, Urmia University \\ of Medical Sciences, Urmia, Iran
}

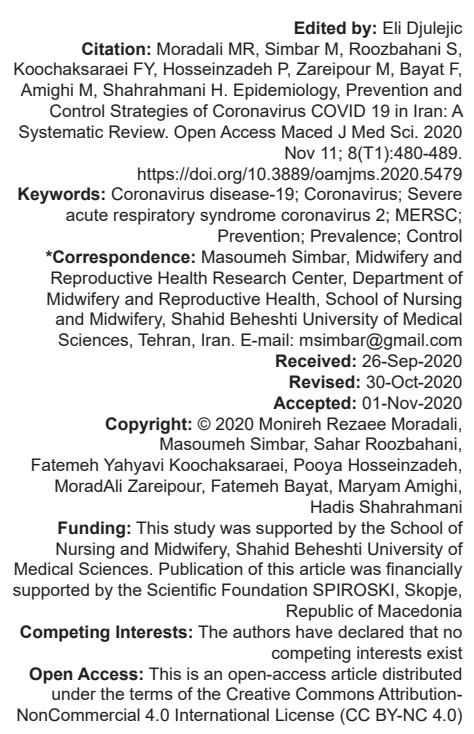

\section{Introduction}

On January 7, 2020, the pathogen was identified as the new coronavirus, now novel coronavirus (nCOV)-2019, or coronavirus disease (COVID-19), which is a virus distinguished from both severe acute respiratory syndrome coronavirus (SARS-CoV) and Middle East Respiratory Syndrome coronavirus (MERSCoV) is distinct [1], [2]. With the spread of this endemic disease in China, other cases of it were observed outside of China [3]. On January 30, 2020, the World Health Organization (WHO) declared it a public health emergency a International public health emergency in the world [4]. As of July 22, 2020, 14,765,256 people have been infected worldwide and 612,054 people have died of the virus. Furthermore, in Iran, according to the WHO report, as of July $22,2020,278,827$ people were infected and 14,634 people died due to the virus [5].

According to current epidemiological research, the incubation period of the disease is 1-14 days (mostly 3-7 days) [6]. The virus is transmitted mainly through respiratory droplets and close contact and is observed in human respiratory epithelial cells for about $96 \mathrm{~h}$, first invading the lungs and causing serous fluid, fibrin exudate, and the formation of a hyaline membrane in the alveoli. Becomes [7], which causes respiratory symptoms such as dry cough, dyspnea, fever and eventually pneumonia, acute respiratory failure, acute respiratory distress syndrome, and other multiple organ 
failures [8], [9]. Furthermore, many patients with COVID19 have gastrointestinal symptoms such as anorexia, abdominal pain, nausea and vomiting, and diarrhea even before the onset of respiratory symptoms [10]. A study found that about $40 \%$ of cases suspected of having COVID-19 had symptoms. Anorexia, 10\% had diarrhea, $8 \%$ had non-specific abdominal pain, and $8 \%$ had nausea and vomiting [11].

The highest mortality and morbidity occurred in the elderly and those with underlying disease. Children and infants are also vulnerable to this disease [12], [13]. According to the National Health Commission of China, the death rate in cases confirmed in China was $2.2 \%$ as of February 4 [14], and among hospitalized patients, the mortality rate was between $11 \%$ and $15 \%$ [6] [15]. To increase the safety of patients and to prevent crossinfection in respiratory infectious patients (such as influenza, COVID-19) can be used contact precautions, air precautions, and droplet precautions [16]. However, treatments supportive drugs are mainly used because there is currently no specific effective treatment [17] and currently the main focus is on the development of new drugs, including antivirals and vaccines [18]. Most people infected with or without mild symptoms can spread the virus and transmit it to others, which is very challenging to prevent the spread of COVID-19. Therefore, strict monitoring is very important to prevent sustainable transmission [19]. In the first period, the new coronavirus, many studies were published on the epidemiology, causes, manifestations, and clinical diagnosis and prevention and control of the virus. However, studies examining prevention and control measures have gradually increased. To minimize the impact of prevalence, it is necessary to study in this field [20].

Countries such as Taiwan and Vietnam have been able to control Corona by doing some strict hygiene measures, including invasive tests, quarantine, tracking contacts with polluted environment, and border monitoring. Likewise, Korea could decrease epidemy by applying invasive tests, quarantine, accompanied by physical distant measures. On the other hand, China could control the epidemy using some strategies such as compulsory quarantine and invasive tests [21]. Moreover, the hygiene system, as well as the community of Iran, has been greatly affected by this epidemy disease [22]. Regarding the severity of the disease, the hygiene system provides some plans to deal with the disease. However, because of the extensive dimensions of the disease, there would have been so much pressure on the hygiene care systems so much that it might not be able to compensate its loss regarding its different dimensions. These dimensions include financial problems, social tension, and hygiene system not responding to the patients. Therefore, cooperation and collaboration of the society with the health system would be influential in control and preventing the disease [23].

Since coronavirus 19 is the third most dangerous pandemic virus emerged in the $21^{\text {st }}$ century and is one of the most prevalent diseases [19], [20] with high mortality and morbidity rate during the disease pandemic which has developed worldwide, although the effective vaccine to prevent it has not yet been made. In the current situation, the only logical way to control the disease and reduce its effects and mortality rate is to use ways to prevent the disease. Hence, the present study was conducted aiming at reviewing the epidemiology, prevention and control strategies relevant to coronavirus 19. Moreover, no similar systematic review study has not been conducted in Iran, this study has been done to review the epidemiology, preventive, and COVID 19 controlling strategies systematically.

\section{Methods}

The aim of this study was to review and classify the findings of Latin and Persian articles relevant to COVID-19 disease, epidemiology, symptoms, ways of control and prevention, as well as existing challenges by reviewing articles published by foreign and Iranian authors in international and local journals about COVID disease-19. In the present review study, articles indexed in Persian and Latin databases of SID Magiran, PubMed, Scopus, Scholar, Web of Science, Embase, MedRxiv, and WHO were examined. The search terms regarding the research topic, based on MESH and syntax, were: COVID19, coronavirus, deltacoronavirus, SARS-CoV-2, MERSCoV, SARS virus, prevention, and prevalence, prevention and control strategies. In total, throughout the present study, on the basis of the above-mentioned keywords, initially 525 articles, reports, and protocols of reputable health organizations were studied, as well as the entry and extract criteria of the articles were scrutinized. After studying the titles and abstracts of articles by the authors of the article and excluding the similar and unrelated items, the relevant items were selected as research items and 38 studies and 5 protocols and reports were reviewed based on the abstract and full text of the articles (Figure 1). Due to the widespread and increasing prevalence of the disease and the changes in the statistics related to the prevalence, the statistics presented in this study are until July 23, 2020. Criteria for selecting articles are:

1. Descriptive, analytical, interventional, and review articles published in the past 5 years.

2. Persian and English articles published in scientific research journals in and out of the country, the full texts of which were available.

3. Articles related to epidemiological studies, control strategies, and prevention of coronavirus 19.

Criteria for excluding articles were: Articles that did not have the full text, articles that did not have clear implementation methods, and articles that focused only on treating the disease rather than ways to prevent and control the disease. 


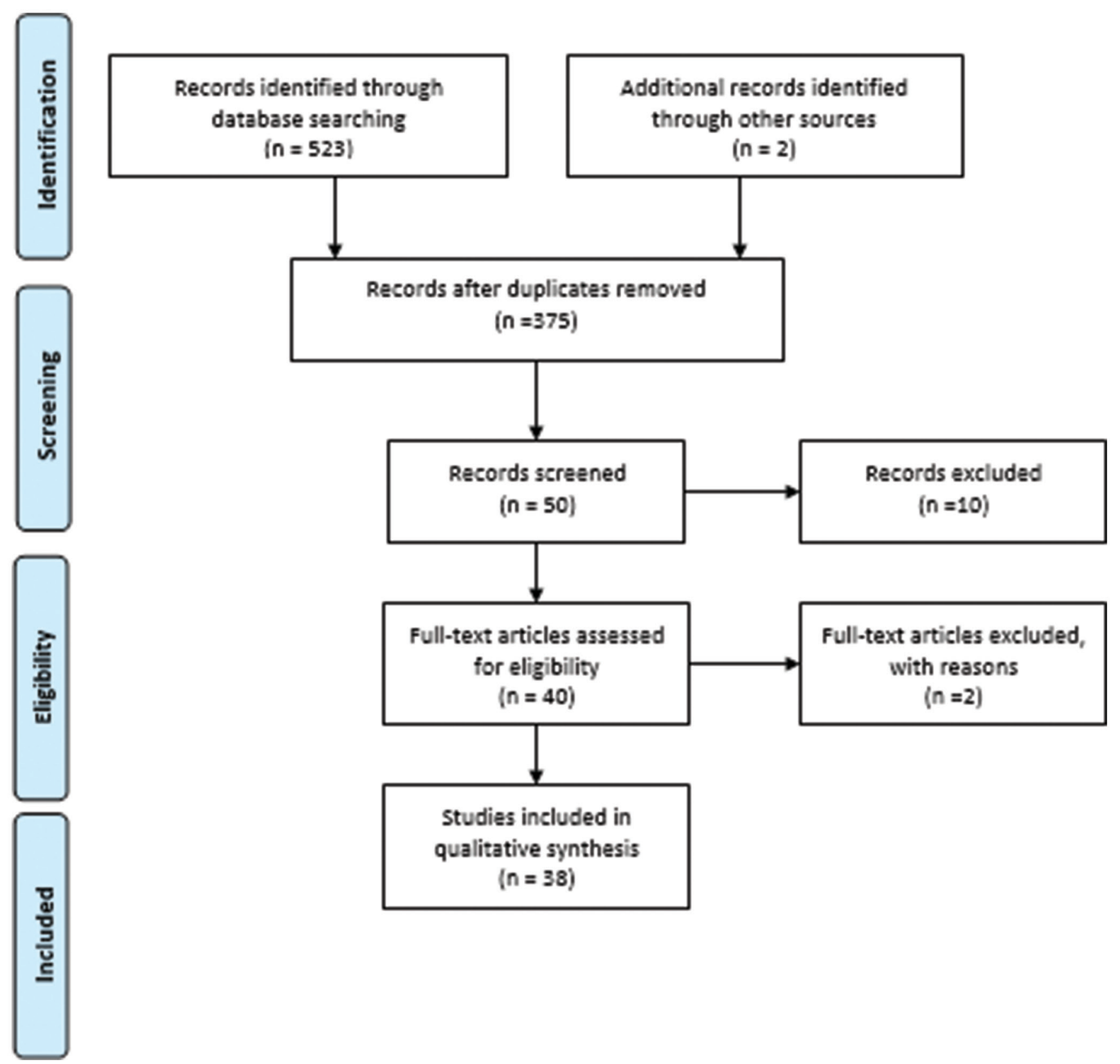

Figure 1: Flowchart for selection of studies

To investigate and analyze the papers elicited from searching databases, which were assessed and qualified according to input and output criteria determined in the methodology, four researchers participated in the research. The flowchart for the selection of studies was illustrated in Figure 1.

\section{Results}

\section{Epidemiology}

Throughout history, many infectious diseases such as HIV, Ebola, Zika, and H1N1 have been emerged [21]. In addition, the Ebola virus outbreak in
2014 and the Zika virus outbreak in 2015 both caused significant damages to countries [21]. The coronavirus is an RNA virus weighing $80-120 \mathrm{~nm}$. It is divided into four types: Alpha coronavirus, beta coronavirus, gamma coronavirus, and delta coronavirus. The recombination rate of COV is high due to high transcription errors. Despite its high mutation, coronavirus has genetic pathogens that occur in humans and animals with a wide range of clinical symptoms from the asymptomatic period to the need for intensive care, infection of the respiratory, gastrointestinal, hepatic, and nervous systems [23]. Human coronavirus was neglected long before the onset of severe acute coronavirus syndrome (SARS-COV) in 2002, and in 2002, in 8096, cases with a $10 \%$ of mortality rate. Fortunately, public health measures, including isolation and quarantine, brought SARS to an end in the summer of 2003. After that, the 
MERS-COV is another coronavirus that has been a constant global health threat since 2012. The disease was reported in South Korea due to an infected person traveling from the Middle East, where in 2015, 186 cases and 36 deaths were reported. As of November 2019, MERS-COV has infected 2944 people and killed 858 [22].

In December 2019, a new beta-coronavirus was temporarily renamed coronavirus 2019. It was later formally renamed as acute respiratory syndrome 2 (SARS-COV2) by the International Committee for the Classification of Viruses (ICTV). Coronavirus 2019 (COVID-19) was named SARS-COV-2 [24]. It is the seventh type of coronavirus that causes infection in humans after SARS-COV and MERS-COV and alike them is a beta subset of coronavirus [23]. On January 30 , the WHO declared COVID-19 as an international emergency concern. nCOV-2019 is the third most dangerous pandemic virus that emerged in the $21^{\text {st }}$ century. It is also one of the epidemic diseases [22].

In no time, scientists began researching the source of new coronavirus, and the first COVID-19 genome was extracted on January 10,2020 , by a research team led by Professor Zhang Zhang. The new virus spread across China within a month of the Chinese New Year. As of December 29, 2019, the first four cases of acute respiratory syndrome of unknown cause were reported in Wuhan, Hubei Province, China, among people associated with the local seafood market [20]. Most of the sufferers were at the exposure of wild animals offered at Wuhan Seafood Wholesale Market. Chickens, snakes, bats, and other domestic animals were also sold in this market. The scientists' findings showed that bats and minks may be two potential hosts for the new coronavirus, while bats were more similar to the new coronavirus in terms of infection pattern than mink. Thereafter, the China Center for Disease Control and Prevention surveyed seafood market products in southern China, concluding that the virus came from wild animals sold in the market. However, Lost's report on 41 infected patients challenged the finding that "no epidemiological link was found between the first patient and the next." The data showed that, in total, 13 of the 41 had no connection to the market. Personto-person transmission of coronavirus was confirmed by Chan et al., who reported that one person infected five members of the family [25]. The new coronavirus outbreak occurred during the Spring Festival in China, China's most famous traditional festival, with nearly 3 billion people attending across China. These conditions have brought about proper conditions for the transmission of this highly contagious disease and severe problems in the prevention and control of the epidemic. The city of Wuhan has been the epicenter of the disease with a population of about 10 million [24]. From December 31, 2020, to January 3, 2020, a total of 44 cases of this new respiratory disease were reported by Chinese authorities to the WHO. As of
July $22,2020,14,765,256$ people have been infected worldwide and 612,054 people have died of the virus. Furthermore, in Iran, according to the WHO report, as of July 22, 2020, 278,827 people were infected and 14,634 people died due to the virus [26]. To date, the main source of infection has been patients with nCOV-2019. Respiratory droplets are the main way of transmission and can also be transmitted through close contact. Although many details, such as the source of the virus and its ability to spread among individuals, are yet unknown, an increasing number of cases indicate the transmission from human to human [27]. The researchers also detected SARS-COV2 in stool, saliva, and urine samples. Based on bioinformatics evidence, it was shown that the gastrointestinal tract could be a potential route for SARS-COV2 infection. In addition, SARS-COV2 was observed in the tear and conjunctival secretions of COVID-19 patients. Meanwhile, a retrospective study of 9 pregnant women with COVID19 showed for the $1^{\text {st }}$ time that the possibility of vertical intrauterine transmission between mothers and infants in late pregnancy was temporarily ruled out. However, research is not adequate and more research is needed in this regard [23]. The infection is transmitted through large droplets sent out by coughing and sneezing by symptomatic patients but may also be transmitted by asymptomatic individuals. These droplets can spread 1-2 $m$ and remain on the surface. The virus can survive in suitable weather conditions for days but can be killed in less than a minute by common disinfectants such as sodium hydrochloride and hydrogen peroxide. The infection can be transmitted to a healthy person either by inhaling these droplets or touching the infected surface and then touching the nose, mouth, and eyes. Studies show that angiotensin 2 receptor acts as a receptor through which the virus enters the respiratory mucosa [28] (Table 1).

\section{Symptoms}

According to the current epidemiological study, the incubation period is generally from 3 days to 7 days and a maximum of 14 days. Unlike SARSCOV, nCOV-2019 is contagious during the commune period [27]. However, many different results have been reported on the incubation period of this disease. Coronavirus SARS-COV2 reproduces efficiently in the upper respiratory tract. Infected people produce a large amount of the virus in their upper respiratory tract during an introductory period, which leads to more spread of the virus to other people. Coronavirus SARS-COV2 also infects cells in the lower respiratory tract and multiplies in these organs, causing lesions in the lower respiratory tract. Infection with the new SARS-COV2 new coronavirus is initially associated with nonspecific and general symptoms such as 
nausea, fatigue, and body aches, fever, and dry cough. Patients with pre-fever may initially have symptoms of nausea and diarrhea. A small number of patients may also have headaches or vomiting of blood. It may even be asymptomatic. Respiratory failure, septic shock, and extrapulmonary organ failure may also occur in severe cases [29]. In a study conducted by Chen et al., $51 \%$ of patients with chronic disease and symptoms such as fever (83\%), cough (82\%), shortness of breath $(31 \%)$, muscle pain $(11 \%)$, fatigue $(9 \%)$, headache $(8 \%)$, sore throat $(5 \%)$, rhinorrhea $(4 \%)$, chest pain $(2 \%)$, diarrhea $(2 \%)$, and nausea and vomiting $(1 \%)$ were reported [15]. Patients with cardiovascular disease, chronic disease, and people aged 60 and over, and men have a higher risk of mortality than the rest of the population. Next clinical findings is including: increasing the number of white blood cells, mostly neutrophils, with a decrease in lymphocytes, platelets and red blood cells. This new coronavirus infection causes more severe illnesses in the elderly, pregnant women, people with chronic debilitating diseases such as diabetes, cardiovascular disease, and malignancy [31].

\section{Prevention and Control}

Lack of specific clinical features, diagnostic microbiological challenge of the new coronavirus outbreak, together with seasonal flu, make difficult COVID-19 to diagnose. Furthermore, clinical signs such as high fever and respiratory symptoms are very similar to previous features of coronavirus. There is currently no specific antiviral treatment or vaccine for SARSCOV2, and clinical treatment of COVID-19 has so far been limited to prophylaxis and palliative care [22]. In the absence of appropriate treatment measurements to overcome the virus, the best ways to deal with are to prevent the spread of infection and control the sources of infection. All sections of society, including employees, employers, and workers, must be fully prepared to repel the coronavirus, even if the corona epidemic has not yet reached that country or region [32]. Prevention of this disease, if divided into two levels, individual and social, will be as follows:

\section{Individual Prevention}

1. Use personal protective equipment such as masks [33]; 2. Do washing and disinfecting hands, especially after touching surfaces in public places; 3. Prevent the spread of respiratory droplets when coughing or sneezing with a mask and other protective equipment; 4. Avoid touching eyes, nose, and mouth; 5. Avoid attending in crowded places and close contact with people; 6. Disinfect the centers that are most exposed to touch [34]; 7. Stay at home when you feel disease; 8. Abstain from smoking and any action that causes damage to the lungs; 9. Follow the government guidelines [35]; 10. Do not share your personal items such as towels, bedding, either at home or at work [36]; 11. Wash your personal items with soap and water after using [37]; 12. Do not shake hands nor hug others when greeting in the workplace or home; 13. Avoid crowded public means of transportation and crowded centers such as hospitals, clinics, and any other public places; 14. Avoid physical contact with pets such as touching, petting, kissing, or eating together; 15 . If animal care is necessary, wear a mask and wash your hands before and after touching pets; 16. Stay home for 14 days in case you are returning from areas with COVID-19 [36]; and 17. Wearing a simple surgical mask by patients [33].

\section{Social Prevention}

1. Restrictions on travel, especially international travel; 2. Screening of people in offices when entering and controlling for signs [34]; 3. Observance of the social distance of at least $2 \mathrm{~m}$ to reduce exposure and cut the transmission chain; 4. Cleaning and disinfecting infected surfaces and items in cities to eliminate and inactivate the virus [38]; 5 . Quarantine and movement restrictions in infected areas; 6. Early identification of infected people; 7. Provide appropriate care for patients; 8. Identify and reduce transmission from animal resources; 9. Minimize social and economic impact through multispectral partnerships [30]; 10. School closures [41]; 11. Use of appropriate equipment, including N95 masks and protective clothing and goggles by health care providers [22]; 12. Preventing sick employees from entering the workplace; 13. Giving compulsory sick leave to sick or suspected employees; 14. Separating and isolating patients and suspects from other employees; 15. Establish proper ventilation systems in workplaces; 16. Use glass or plastic barrier between staff and clients or visitors; 17 . Use of disposable tools and equipment; 18. Continuous training the employees regarding the observance of hygienic rules, handwashing, and how to use protective equipment; 19. Reducing staff working hours; 20. Reducing unnecessary missions and trips of employees; and 21. Restricting staff gatherings in sports and religious centers and holding remote meetings [32].

Quarantine alone is not enough to prevent the spread of COVID-19. A lot of countries have done controlling measurements, including a combination 
Table 1: Research on epidemiology and prevention and control strategies of coronavirus COVID 19

\begin{tabular}{|c|c|c|c|c|c|c|}
\hline Title & Authors & Year & Study selection & Samples & Results & Ref. \\
\hline $\begin{array}{l}\text { Unique epidemiological and } \\
\text { clinical features of the emerging } \\
2019 \text { novel coronavirus } \\
\text { pneumonia (COVID-19) implicate } \\
\text { special control measures }\end{array}$ & Wang et al. & 2020 & Review & 92 articles & $\begin{array}{l}\text { Majority of infected individuals with no or mild symptoms can release } \\
\text { viruses and spread viruses to others, which is extremely challenging } \\
\text { for preventing the spread of COVID-19. Active interventions, including } \\
\text { nutrition supplement, symptomatic treatment, and antiviral treatment } \\
\text { are critical for mild patients as well as severe patients. Prophylactic } \\
\text { vaccination is highly demanded for future prevention of emerging } \\
\text { coronavirus related epidemics or pandemics }\end{array}$ & [19] \\
\hline
\end{tabular}

Epidemiology, causes, clinical manifestation and diagnosis, prevention and control of coronavirus disease (COVID-19) during the early outbreak period: A scoping review

Pandemic fear and COVID-

19: Mental health burden and strategies

\section{9 novel coronavirus (2019-} $\mathrm{nCoV}$ ) outbreak: A new challenge

A review of coronavirus disease-2019 (COVID-19)

2019 novel coronavirus (COVID19) outbreak: A review of the current literature

2019 novel coronavirus: Where we are and what we know

A rapid advice guideline for the diagnosis and treatment of 2019 novel coronavirus (2019-nCoV) infected pneumonia A review of the 2019 novel coronavirus (COVID-19) based on current evidence Novel coronavirus disease 2019 (COVID-19): An emerging infectious disease in the $21^{\text {st }}$ century

COVID-19 and substance use disorders: Recommendations to a comprehensive healthcare response

Novel coronavirus 2019-nCoV: Prevalence, biological, and clinical characteristics comparison with SARS-CoV and MERS-CoV

Approaches for COVID-19 infection control in the workplace Occupational Medicine. 2019

Review on the symptoms, transmission, therapeutics options and control the spread of the disease of COVID-19

A review of the new 21 st century coronavirus (novel coronavirus-2019)

Coronavirus: Origins, signs, prevention, and management of

patients outbreak and the strategy for Prevention
Adhikari et al. $2020 \quad$ Review 65 articles

This study shows a holistic picture of the current research in response to the outbreak of COVID-19. Most studies have focused on the epidemiology and potential causes. However, studies exploring prevention and control measures have begun to gradually increase. Studies in this domain are urgently needed to minimize the impact of the outbreak

$\begin{array}{llll}\text { Ornell et al. } & 2020 & \text { Review } & 26 \text { articles }\end{array}$

It is extremely necessary to implement public mental health policies in conjunction with epidemic and pandemic response strategies before, during and after the event. Mental health professionals must be on the front line and play a leading role in emergency planning and managemen teams

Lupia et al. $2020 \quad$ Review 225 articles

The new 2019-nCoV epidemic is mainly associated with respiratory disease and few extrapulmonary signs. However, there is a low rate of

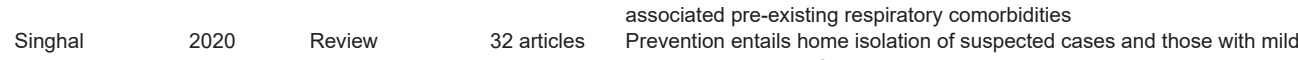
illnesses and strict infection control measures at hospitals that include contact and droplet precautions. The virus spreads faster than its two ancestors, the SARS-CoV and MERS-CoV, but has lower fatality

Coronaviruses will cause spreads and outbreaks with differentmutant strains similarly in the coming years. With increased scientific collaboration, which is a result of globalization, we may have more powerful means of fighting against coronaviruses, in which we know the genome structure very well in the future $\begin{array}{llll}\begin{array}{l}\text { Cheng and } \\ \text { Shan }\end{array} 2020 \quad \text { Review } & 32 \text { articles } & \begin{array}{l}\text { By fitting the number of infections with a single-term exponential model, we } \\ \text { report that the infection is spreading at an exponential rate, with a doubling } \\ \text { period of } 1.8 \text { days }\end{array}\end{array}$

Jin et al. $\quad 2020 \quad$ Review $\quad 38$ articles

This rapid advice guideline is suitable for the first frontline doctors and nurses, managers of hospitals and healthcare sections, community residents, public health persons, relevant researchers, and all person who are interested in the 2019-nCoV

This review in the hope of helping the public effectively recognize and deal with the 2019 novel coronavirus (SARS-CoV-2) and providing a reference for future studies

Tavakoli et al. $2020 \quad$ Review 53 articles human coronaviruses; however, the mortality rate of COVID-19 is lower than that of other coronaviruses diseases such as SARS or MERS and other viruses. At present, due to the lack of an effective treatment and vaccine, the best way to deal with the COVID-19 disease is to prevent transmission and spread of the virus and to execute personal protective measures

Mokri et al. $2020 \quad$ Review

128 articles

In this paper, an international group of experts on addiction medicine, infectious diseases, and disaster psychiatry explore the possible raised concerns in this issue and provide recommendations to manage the comorbidity of COVID-19 and substance use disorder (SUD)

Meo et al. $2020 \quad$ Review

18 articles

The 2019-nCoV has epidemiological and biological character

it moking [33] it more contagious than SARS-CoV and MERS-CoV. Although the fatality rate of MERS-CoV was higher than them. The major clinical manifestations in coronavirus infections 2019-nCoV are fever, chills, cough, shortness of breath, generalized myalgia, malaise, drowsy, diarrhea, confusion, dyspnea, and pneumonia. Global health authorities should take immediate measures to prevent the outbreaks of such emerging and reemerging pathogens across the globe to minimize the disease burden locally and globally

Rafeemanesh $2019 \quad$ Review

19 articles

All members of the society, including employers, employees and laborers, should be completely ready to overcome the virus, even if the epidemic has not been spreading in that country or area. This point can be effective on the reduction of lost workdays, work absenteeism, and prevent the spread of the virus in the community

22 articles The extensive functions have been carried out to reduce person-to-person transmission of COVID-19. In this review, the symptoms, epidemiology, transmission, pathogenesis, phylogenetic analysis, and future directions to control the spread of this fatal disease have been presented

Ghaderi et al. $2020 \quad$ Review 47 articles Accordingly, it is considered a serious global threat and all necessary precautions should be taken in the event of any suspected case. Experiences from (MERS) and (SARS) highlight the importance of rapidly finding the source for 2019-nCoV to stem the ongoing outbreak It is important that, in these difficult times, nurses understand the symptoms of COVID-19, how to prevent its spread, and are up-to-date on the guidance on critical care

Sajed and $2020 \quad$ Review 6 articles Eradication of highly contagious SARS-CoV-2 virus that causing the ongoing deadly pandemic COVID-19 demands individual attention and awareness is necessary regarding the route and mode of transmission across the bounders throughout entire world. Proper handwashing, staying in-home, and maintaining the social distance are proved to be the most effective preventive measures which are immediate solution to save human being from this unseen enemy
(Contd...) 
Table 1: (Continued)

\begin{tabular}{|c|c|c|c|c|c|c|}
\hline Title & Authors & Year & Study selection & Samples & Results & Ref. \\
\hline $\begin{array}{l}\text { Modeling transmission and control } \\
\text { of the COVID-19 pandemic in } \\
\text { Australia }\end{array}$ & Chang et al. & 2020 & Review & 58 articles & $\begin{array}{l}\text { School closures are not found to bring decisive benefits unless coupled } \\
\text { with high level of social distancing compliance. We report an important } \\
\text { transition across the levels of social distancing compliance, in the range } \\
\text { between } 70 \% \text { and } 80 \% \text { levels. This suggests that compliance of below } \\
70 \% \text { is unlikely to succeed for any duration of social distancing, while } \\
\text { compliance at the } 90 \% \text { level is likely to control the disease within } 13-14 \\
\text { weeks when coupled with effective case isolation and international travel } \\
\text { restrictions }\end{array}$ & [39] \\
\hline $\begin{array}{l}2019 \text { novel coronavirus (COVID- } \\
\text { 19) pandemic: Built environment } \\
\text { considerations to reduce } \\
\text { transmission }\end{array}$ & Dietz et al. & 2020 & Review & 96 articles & $\begin{array}{l}\text { We hope this information can help to inform the decisions and infection } \\
\text { control mechanisms that are implemented by corporate entities, federal, } \\
\text { state, county, and city governments, universities, school districts, places } \\
\text { of worship, prisons, health care facilities, assisted living organizations, } \\
\text { daycares, homeowners, and other building owners and occupants to } \\
\text { reduce the potential for transmission through BE-mediated pathways }\end{array}$ & [40] \\
\hline
\end{tabular}

of increasing hygienic acts, travel restrictions, case diagnosis, contact tracking, and remote activities. Their overall goal is to reduce the number of contacts of the population, thus preventing the transmission of infection [24]. While many common precautions are being taken to stop the spread of SARS-COV2, other less common transmission pathways should be considered and taken to reduce the spread [42]. The effectiveness of school closures is limited, although a 2-week delay in the peak of the epidemic does not have a significant effect on the peak size of the disease [41]. The greatest risk of COVID-19 is transmission to health care workers. At the outbreak of SARS in 2002, $21 \%$ of these people were affected by health care workers. Protecting the transmission of infection to other patients is important. Patients should be placed in separate rooms or next to each other. Negative pressure in rooms is generally not required [22].

\section{Discussion}

Research studies which assess the rate of COVID-19 interventions are limited and even if they are available, they either consider just one intervention, or they had been done in other fields of study. Therefore, the present study would be influential in dealing with disease by providing some major perspectives elicited from the collection of papers through investigating controlling, as well as personal and social preventive strategies.

Numerous features of the virus make it difficult to prevent, including non-specific features of the disease, infection even before the onset of symptoms during the incubation period, transmission from asymptomatic individuals, long incubation period, prolongation of the disease, and transmission even after its clinical improvement [26].

There is no single intervention to adequately control or reduce the epidemic of the disease. A combination of several influential measures such as keeping the social distance, doing several diagnostic tests, and identifying positive cases would probably decrease the burden of the epidemic. However, it is essential to start synergic treatment earlier and continue appropriately. If following social distance and strict measures to diagnose the cases and tracking them start earlier but stops in $<6$ months, the disease burden and mortality rate would increase again, growing the demand for receiving hygienic care. While in doing early, invasive and long interventions, it would be easier to control the disease for a longer time. It seems that diagnosing marked patients, separating, intervening proceeding is the footstone of each successful controlling strategy [23].

Regarding recent findings, almost half of disease transmissions maybe before the symptom occurrence phase [43]. Therefore, keeping the social distant and keeping schools off to reduce personal contacts are logical and important ways. While dealing with an uncontrollable disease, hygienic systems of the countries with limited sources are significantly under pressure; thus, the morbidity and mortality rate would be 2 times of expected amount. If an uncontrollable disease is updating itself, even adding the number of hospital beds significantly does not work to decrease the mortality rate [23].

Several challenges have been posed by the COVID-19 epidemic, one of which is that the true extent of COVID-19 and the scale of its possible prevalence are not known precisely, and the actual number of infected and suspected patients is not identifiable [44].

Extension of corona resulted in a decrease of enormous economic and social offices all over the world. To decrease the financial loss resulted from the disease, as well as to support the small, stricken careers, most countries consider protective acts such as grants and tax reductions [45]. The propose theory is that it is possible that people are tired of following the long intervention; moreover, doing social distance can result in unwanted hygienic, economic, and welfare consequences, the subject that would probably affect strongly on a lot of countries who do not care on following the social security principles [46], [47].

The mortality and transmission rate of patients with COVID-19 vary in different findings [48]. 
On the other hand, more studies should be done on the following: How the virus is easily transmitted among people? How can it affect vulnerable subgroups such as the elderly or people with chronic diseases? What is the source of the virus? And how can it spread worldwide in such a short period of time [49]. Another challenge is whether nCOV-2019 disease is transmitted directly from bats or through an intermediate host. Wang et al. stated that one of the challenges is that "time is so limited that we cannot fully account for all the clinical problems with this emergency; second, much of the evidence from data retrieval is indirect" [5]. One of the existing problems is social media. In addition to sharing content quickly, social media also quickly spreads rumors, misunderstandings, and intimidation [20]. Only extensive research can be the key to solving the existing challenges and we hope that future studies will focus on the development of COVID-19 vaccines and effective drugs to treat them to reduce mortality.

\section{Conclusion}

According to studies and reports, the best way to overcome new corona disease is to prevent new cases and control the disease. Given the unknown characteristics of COVID-19, it is recommended that all organizations work to prevent and control the disease and break the transmission chain. To achieve this goal, the best solution is to educate the community, provide accurate information, provide sufficient personal protective equipment, allocate funds to fight the disease, abolish all communities, and emphasize on citizens staying home and washing their hands regularly, observe social distance, providing adequate diagnostic and treatment facilities, establishing fever measuring rooms in all stations, airports and public places, and finally identify suspected cases and quarantining.

The uncontrollable epidemic of COVID-19 has the potential to lead to a huge amount of death, strengthening with unanswered demand to hygienic measures. Results indicate that the best strategy is to control facing epidemic is a combination of interventions aiming at diagnose, reducing the contact, through some physical actions, and doing quarantine for infected people. Restricting the measures would prevent the extension of the epidemic, but if additional control measures would not be implemented, it would probably low in value.

It is essential that all managers, employers, and business owners be provided with the necessary information and training on prevention and control of COVID 19 disease based on health guidelines and protocols to reduce the number of patients and prevent the spread of the disease in society.

\section{References}

1. Zhu N, Zhang D, Wang W. A novel coronavirus from patients with pneumonia in China, 2019. N Engl J Med. 2020;382(8):727-33. PMid:31978945

2. Tan W, Zhao X, Ma X, Wang W, Niu P, Xu W, et al. A nove coronavirus genome identified in a cluster of pneumonia casesWuhan, China 2019. China CDC Weekly. 2020;2(4):61-2. https://doi.org/10.46234/ccdcw2020.017

3. Liu K, Chen Y, Wu D, Lin R, Wang Z, Pan L. Effects of progressive muscle relaxation on anxiety and sleep quality in patients with COVID-19. Complement Ther Clin Pract. 2020;39:101132. https://doi.org/10.1016/j.ctcp.2020.101132

PMid:32379667

4. Chen N, Zhou M, Dong X, Qu J, Gong F, Han Y, et al Epidemiological and clinical characteristics of 99 cases of 2019 novel coronavirus pneumonia in Wuhan, China: A descriptive study. Lancet. 2020;395(10223):507-13. https://doi.org/10.1016/ s0140-6736(20)30211-7

PMid:32007143

5. Coronavirus Disease (COVID-19) Situation Reports. Available from: $\quad$ https://www.who.int/emergencies/diseases/novelcoronavirus-2019/situation-reports. [Last accessed on $2020 \mathrm{Jul}$ 22].

6. Lu H, Stratton CW, Tang YW. Outbreak of pneumonia of unknown etiology in Wuhan, China: The mystery and the miracle. J Med Virol. 2020;92(4):401-2. https://doi.org/10.1002/jmv.25678 PMid:31950516

7. Wu YC, Chen CS, Chan YJ. The outbreak of COVID-19: An overview. J Chin Med Assoc. 2020;83(3):217.

PMid:32134861

8. Li Q, Guan X, Wu P, Wang X, Zhou L, Tong Y, et al. Early transmission dynamics in Wuhan, China, of novel coronavirusinfected pneumonia. N Engl J Med. 2020;382(13):1199-207. PMid:31995857

9. Wang D, Hu B, Hu C, Zhu F, Liu X, Zhang J, et al. Clinical characteristics of 138 hospitalized patients with 2019 novel coronavirus-infected pneumonia in Wuhan, China. JAMA. 2020;323(11):1061-9. https://doi.org/10.1001/jama.2020.1585 PMid:32031570

10. Gu J, Han B, Wang J. COVID-19: Gastrointestinal manifestations and potential fecal-oral transmission. Gastroenterology. 2020;158(6):1518-9. https://doi.org/10.1053/j. gastro.2020.02.054

PMid:32142785

11. Miri SM, Roozbeh F, Omranirad A, Alavian SM. Panic of buying toilet papers: A historical memory or a horrible truth? Systematic Review of Gastrointestinal Manifestations of COVID-19. Hepat Mon. 2020;20(3):e102729. https://doi.org/10.5812/ hepatmon.102729

12. Shen $K$, Yang $Y$, Wang $T$, Zhao $D$, Jiang $Y$, Jin $R$, et al. Diagnosis treatment, and prevention of 2019 novel coronavirus infection in children: Experts' consensus statement. World J Pediatr. 2020;16(3):223-31 PMid:32034659

13. Shen KL, Yang YH. Diagnosis and treatment of 2019 nove coronavirus infection in children: A pressing issue. World $J$ 
Pediatr. 2020;16(3):219-21.

PMid:32026147

14. National Health Commission. NHS Press Conference 2020 Beijing, China: National Health Commission (NHC) of the People's Republic of China. Available from: http://www.nhc. gov.cn/xcs/xwbd/202002/235990d202056cfcb202043f202004a 202070d202007f209703b202113c202000.shtml.

[Last accessed on 2020 June 20]

15. Huang C, Wang Y, Li X, Ren L, Zhao J, Hu Y, et al. Clinical features of patients infected with 2019 novel coronavirus in Wuhan, China. Lancet. 2020;395(10223):497-506. https://doi. org/10.1016/s0140-6736(20)30183-5

16. World Health Organization. Q\&A on Coronaviruses. Geneva: World Health Organization; 2020.

17. Chen X, Shang Y, Yao S, Liu R, Liu H. Perioperative care provider's considerations in managing patients with the COVID-19 infections. Transl Perioper Pain Med. 2020;7:216-24. https://doi.org/10.31480/2330-4871/116

18. Mehta P, McAuley DF, Brown M, Sanchez E, Tattersall RS, Manson JJ, et al. COVID-19: Consider cytokine storm syndromes and immunosuppression. Lancet. 2020;395(10229):1033. https://doi.org/10.1016/s0140-6736(20)30628-0 PMid:32192578

19. Wang $Y$, Wang $Y$, Chen $Y$, Qin $Q$. Unique epidemiological and clinical features of the emerging 2019 novel coronavirus pneumonia (COVID-19) implicate special control measures. J Med Virol. 2020;92(6):568-76. https://doi.org/10.1002/ jmv. 25748

PMid:32134116

20. Adhikari SP, Meng S, Wu YJ, Mao YP, Ye RX, Wang QZ, et al. Epidemiology, causes, clinical manifestation and diagnosis, prevention and control of coronavirus disease (COVID-19) during the early outbreak period: A scoping review. Infect Dis Poverty. 2020;9(1):1-12. https://doi.org/10.1186/s40249-020-00646-x PMid:32183901

21. Pandey KR, Subedee A, Khanal B, Koirala B. COVID-19 Control Strategies and Intervention Effects in Resource Limited Settings: A Modeling Study. Available from: http:// www.medrxiv.org. [Last accessed on 2020 Oct 27]. https://doi. org/10.1101/2020.04.26.20079673

22. Samadipour E. Factors Influencing Iranians' Risk Perception of Covid-19. Available from: http://www.militarymedj.ir/browse. php?a_id=2483\&sid=1\&slc_lang=en\&ftxt=1. [Last accessed on 2020 Oct 27]

23. Zareipour MA, Kalejahi JN. The role of social participation in controlling and preventing of coronavirus 2019 disease in Iran. J Med Sci. 2020;8(T1):134-6.

24. Ornell F, Schuch JB, Sordi AO, Kessler FH. Pandemic fear and COVID-19: Mental health burden and strategies. Braz J Psychiatry. 2020;42(3):232-5. https://doi. org/10.1590/1516-4446-2020-0008 PMid:32267343

25. Lupia T, Scabini S, Pinna SM, Di Perri G, De Rosa FG, Corcione S. 2019-novel coronavirus outbreak: A new challenge. J Global Antimicrob Resist. 2020;21:22-7. https://doi. org/10.1016/j.jgar.2020.02.021

26. Singhal T. A review of coronavirus disease-2019 (COVID-19). Indian J Pediatr. 2020;87(4):281-6. PMid:32166607

27. Sahin AR, Erdogan A, Agaoglu PM, Dineri Y, Cakirci AY, Senel ME, et al. 2019 novel coronavirus (COVID-19) outbreak: A review of the current literature. EJMO. 2020;4(1):1-7. https:// doi.org/10.14744/ejmo.2020.12220

28. Cheng ZJ, Shan J. 2019 Novel coronavirus: Where we are and what we know; 2020. Available from: http://www.preprints. org. [Last accessed on 2020 Jul 27]. https://doi.org/10.20944/ preprints202001.0381.v1

29. Jin YH, Cai L, Cheng ZS, Cheng H, Deng T, Fan YP, et al. A rapid advice guideline for the diagnosis and treatment of 2019 novel coronavirus (2019-nCoV) infected pneumonia (standard version). Mil Med Res. 2020;7(1):4.

30. Wang LS, Wang YR, Ye DW, Liu QQ. A review of the 2019 novel coronavirus (COVID-19) based on current evidence. Int J Antimicrob Agents. 2020;55(6):105948. https://doi. org/10.1016/j.ijantimicag.2020.105948

31. Tavakoli A, Vahdat K, Keshavarz M. Novel coronavirus disease 2019 (COVID-19): An emerging infectious disease in the $21^{\text {st }}$ century. ISMJ. 2020;22(6):432-50.

32. Farhoudian A, Baldacchino A, Clark N, Gerra G, Ekhtiari H, Dom G, et al. COVID-19 and substance use disorders: Recommendations to a comprehensive healthcare response. An international society of addiction medicine (ISAM) practice and policy interest group position paper. Auton Neurosci. 2020;11(2):129-46. https://doi.org/10.32598/bcn.11.covid19.1

33. Meo S, Alhowikan A, Al-Khlaiwi T, Meo I, Halepoto D, Iqbal M, et al. Novel coronavirus 2019-nCoV: Prevalence, biological and clinical characteristics comparison with SARS-CoV and MERSCoV. Eur Rev Med Pharmacol Sci. 2020;24(4):2012-9. PMid:32141570

34. Rafeemanesh E, Rahimpour F, Memarzadeh M. Approaches for Covid-19 infection control in the workplaces. Occup Med. 2019;11(4):3653. https://doi.org/10.18502/tkj.v11i4.3653

35. Irani M. Review on the symptoms, transmission, therapeutics options and control the spread of the disease of COVID-19. Alborz Univ Med J. 2020;9(2):171-80

36. Ghaderi MS, Nedae B, Abedi F, Biglari G, Mafi MH. A Review of the New 21st Century Coronavirus (novel coronavirus-2019). 2020; Navid No 23: 20-34. Spring Framework.

37. Hill B. Coronavirus: Origins, signs, prevention and management of patients. $\mathrm{Br} J$ Nurs. 2020;29(7):399-402. https://doi. org/10.12968/bjon.2020.29.7.399 PMid:32279552

38. Sajed AN, Amgain K. Corona virus disease (COVID-19) outbreak and the strategy for prevention. Eur J Med Sci. 2020;2(1):1-3. https://doi.org/10.46405/ejms.v2i1.38

39. Sajed AN, Amgain K. Corona virus disease (COVID-19) outbreak and the strategy for prevention. Eur J Med Sci. 2020;2(1): 1-3.

40. Chang SL, Harding N, Zachreson C, Cliff OM, Prokopenko M. Modelling transmission and control of the COVID-19 pandemic in Australia. ArXiv Preprint arXiv:2003. Guidelines for the second step in the fight against Covid 19 in Iran.

41. Dietz L, Horve PF, Coil DA, Fretz M, Eisen JA, Van Den Wymelenberg K. 2019 novel coronavirus (COVID-19) pandemic: Built environment considerations to reduce transmission. Msystems. 2020;5(2):e00245-20. https://doi.org/10.1128/ msystems.00245-20

PMid:32265315

42. Guidelines for the second step in the fight against Covid 19 in Iran. https://www.behdasht.gov.ir/step2corona Available from: https://www.behdasht.gov.ir/step2corona.

43. Lyng GD. Identifying optimal COVID-19 testing strategies for schools and businesses: Balancing testing. Nat Med. 2020;26(5):672-5.

44. Fang $\mathrm{Y}$, Nie $\mathrm{Y}$, Penny $\mathrm{M}$. Transmission dynamics of the COVID-19 outbreak and effectiveness of government interventions: A data-driven analysis. J Med Virol. 2020;92(6):645-59. https://doi.org/10.1002/jmv.25750 PMid:32141624

45. Rafeemanesh E, Ahmadi F. A Review on Recent Guidelines and Articles about Prevention of Covid-19 Infection in Dental 
Settings. Available from: http://www.eprints.mums.ac.ir/25629. [Last accessed on 2020 Oct 28].

46. Roberts M, Andreasen V, Lloyd A, Pellis L. Nine challenges for deterministic epidemic models. Epidemics. 2015;10:49-53. https://doi.org/10.1016/j.epidem.2014.09.006 PMid:25843383

47. Blackwood JC, Childs LM. An introduction to compartmental modeling for the budding infectious disease modeler. Lett
Biomathematics. 2018;5(1):195-221. https://doi.org/10.1080/23 737867.2018.1509026

48. Sun $P$, Lu X, Xu C, Sun W, Pan B. Understanding of COVID-19 based on current evidence. J Med Virol. 2020;92(6):548-51. https://doi.org/10.1002/jmv.25722

49. Wu D, Wu T, Liu Q, Yang Z. The SARS-CoV-2 outbreak: What we know. Int J Infect Dis. 2020;94:44-8. https://doi.org/10.1016/j. ijid.2020.03.004 